REVISTA DE GESTAOE SEEREETRRADO

MANAGEMENT AND AdMINISTRATIVE PROFESSIONAL REVIEW
Organização: SINSESP

Editora Científica: Dra. Cibele B. Martins

Avaliação: Double Blind Review pelo SEER/OJS

Revisão: Gramatical, normativa e de formatação

Data de recebimento do artigo: 9-1-2017

Data de aceite do artigo: $17-1-2018$

DOI: http://dx.doi.org/10.7769/gesec.v9i1.634

\title{
Evidências da adaptação de profissionais de secretariado ao trabalho virtual
}

\begin{abstract}
Naira Fanzeres
Pós-graduada em Gestão Estratégica de Secretariado. E-mail: naira_fanzeres@hotmail.com (Brasil)

\section{Luciana Campos Lima}

Doutora em Administração pela Faculdade de Economia, Administração e Contabilidade (FEA/USP). Pesquisadora do CRANET - Cranfield Network HRM. E-mail: lucamposlima@hotmail.com (Brasil)
\end{abstract}

\section{RESUMO}

Este artigo buscou verificar como se dá o ajuste, pelo profissional de secretariado, ao trabalho virtual. Para isso, aplicou-se o questionário padronizado (Raghuram et $a l ., 2001$ ) em uma amostra de 31 profissionais que possuem vínculo empregatício e que trabalham virtualmente. $\mathrm{O}$ instrumento de coleta de dados contempla 18 afirmações fechadas com escala tipo Likert divididas em quatro seções: independência no trabalho virtual, clareza nas avaliações, conexão organizacional e confiança interpessoal. Dentre os achados, destacam-se: (1) a clareza do sistema de avaliações, referente aos fatores estruturais e (2) a relação de confiança interpessoal, pertencente aos fatores relacionais. Isso porque esses aspectos apresentam os maiores índices de concordância por parte dos participantes. Verificou-se que $87 \%$ mostram-se satisfeitos em trabalhar de forma virtual, demonstrando o ajuste a esse tipo de modalidade de trabalho flexível. Além disso, $70 \%$ dos respondentes afirmam terem tido aumento de produtividade e $77 \%$ defendem que há equilíbrio entre vida pessoal e profissional, indicando que a telepressão não parece afetar o público envolvido neste estudo. Almejou-se contribuir para o aprofundamento dessa temática proporcionando uma discussão mais assertiva sobre a realidade dos profissionais de secretariado, além de fornecer informações aos cursos de formação profissional.

PALAVRAS-CHAVE: Secretariado virtual. Teletrabalho. Secretariado Executivo. Trabalho virtual. 


\section{Evidence of administrative professional adaptation of the virtual work}

\section{ABSTRACT}

This article tries to verify how the adjustment by the executive advisor is made through virtual work. To that end, a sample of thirty-one professionals who work virtually as executive advisors answered to a standardized questionnaire (Raghuram et al., 2001). This consists of eighteen Likert-type closed statements divided into four sections: independence in virtual work, clarity in assessments, organizational connection and interpersonal trust. Among the findings, it is worth noting that clarity of scores, referring to structural factors of virtual work, and interpersonal trust, belonging to the main relational factors, present the highest index of agreement among the participants. It was found that $87 \%$ are satisfied to work in a virtual way and this finding demonstrates the adjustment to a type of flexible working modality. Moreover, this adjustment is reinforced by the fact that, although $70 \%$ of the respondents say they have increased productivity, meaning the pressure of virtual work does not seem to affect them and $77 \%$ defend that there is a balance between personal and professional life when working in a virtual way. It was hoped to contribute to a more profound study about this theme by providing a more assertive discussion about a reality of the executive advisors, besides providing information to professional training courses.

KEYWORDS: Virtual Executive Assistant, Offsite Work, Executive Secretariat, Virtual Work.

\section{Como referenciar em APA:}

Fanzeres, N., \& Lima, L. C. (2018). Evidências da adaptação de profissionais de secretariado ao trabalho virtual. R.G.Secr.,GESEC, 9(1). doi: http://dx.doi.org/10.7769/gesec.v9i1.634

\section{Como referenciar em ABNT:}

FANZERES, N.; LIMA, L. C. Evidências da adaptação de profissionais de secretariado ao trabalho virtual. R.G.Secr.,GESEC, v. 9, n. 1, 2018. doi: http://dx.doi.org/10.7769/gesec.v9i1.634
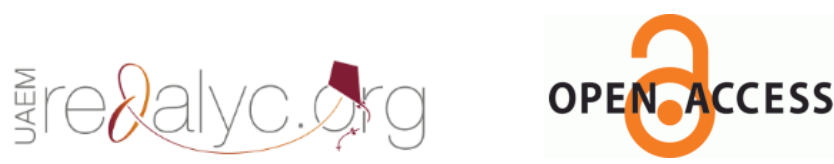
Fanzeres, N., \& Lima, L. C. (2018).

\section{Introdução}

O século XXI é conhecido como o século da globalização e da informação. Com os avanços tecnológicos criaram-se integração cultural e comunicação instantânea com o mundo todo, facilitando o intercâmbio econômico e novas modalidades de trabalho, dentre elas, o trabalho virtual. Este tem como principal característica a possibilidade da prestação de serviço distante do escritório central e sem contato pessoal com colegas de trabalho. É possível oferecer serviços apenas conectado por meio da internet, em seu próprio domicílio ou em lugares criados para essa modalidade, de forma a eliminar custos com estrutura e até mesmo diminuir os gastos com a contratação de funcionários (Winter, 2005).

Johns e Gratton (2013) apontam que, em alguns anos, mais de 1.3 bilhão de pessoas trabalharão de forma virtual, levando o mercado de trabalho a fazer alterações em sua legislação e atraindo cada vez mais profissionais que possuem interesse em ter menos vínculo empregatício e gerir de outra forma seu próprio dia de trabalho. Se, em 2013, essa argumentação apresentava-se, para alguns, como uma previsão de futuro distante, em 2015 a pesquisa realizada pela WorldatWork sobre tendências de flexibilidade no trabalho com 375 empresas localizadas, predominantemente, na América do Norte demonstram que o trabalho virtual é uma realidade.

Sendo considerado o trabalho flexível mais utilizado desde 2010, o trabalho virtual neste estudo, tratado como sinônimo de teletrabalho e homeoffice, já é oferecido a alguns ou a todos os funcionários em mais de $80 \%$ das organizações, conforme identificou a pesquisa WorldatWork (2015). Além disso, outros achados chamam a atenção, tais como: 1) 66\% das empresas compram laptops para seus teletrabalhadores; 2) $86 \%$ utilizam sua rede virtual privada como instrumento de trabalho; 3) 70\% usam software de comunicação e colaboração, como o WebEx e 4) 61\% adotam os sistemas telefônicos. Embora muitos gerentes ainda achem difícil estimar a produtividade dos teletrabalhadores, $48 \%$ acreditam que estes são tão produtivos quanto os profissionais fisicamente alocados na sede.

No contexto brasileiro, um estudo realizado pela SAP Consultoria em Recursos Humanos, com 325 organizações, identificou que 68\% das empresas são praticantes de teletrabalho e $80 \%$ destas adotaram a prática nos últimos cinco anos. A existência da prática ocorre em empresas públicas e privadas, sendo 67\% multinacionais. Os participantes afirmam que os principais ganhos oriundos da implantação do homeoffice são a produtividade (54\%) e o aumento da satisfação e do engajamento de colaboradores (85\%). 
É importante destacar que a emergência desse modelo de trabalho não se concentra apenas no setor privado, a empresa de processamento de dados (Serpro), vinculada ao Ministério da Fazenda, além de ter sido a primeira a implementar o teletrabalho domiciliar, em 2013, já possuía 31 funcionários trabalhando remotamente, resultando em um ganho em produtividade de 10,5\% (Silva, 2015).

Os impactos da virtualidade perpassam por diversos núcleos profissionais, entre eles o do secretariado. Nesse sentido, observa-se, que a literatura acadêmica sobre essa temática ainda é escassa ou praticamente inexistente. Em um estudo bibliométrico realizado entre os anos de 2005 a 2012 e conduzido por Iizuka e Almeida (2014) não foi identificado nenhum material que pudesse contribuir para a referida temática. Os assuntos dos artigos analisados variam entre contexto e atuação profissional, formação acadêmica e ensino e aprendizagem, sendo estes considerados pelos autores como as principais temáticas constitutivas do campo de estudo sobre secretariado.

Os resultados de outro estudo bibliométrico, realizado por Durante e Pontes (2015), apontaram que 73 artigos foram publicados na GeSec - Revista de Gestão e Secretariado entre os anos de 2010 e 2013, contudo, nenhum deles abordou o trabalho virtual do profissional de secretariado. Martins et al. (2014) escreveram um artigo sobre o suporte fornecido pelas ferramentas de tecnologia da informação e comunicação às atividades de secretariado executivo, entretanto, não se aproximaram da temática discutida neste artigo.

Sendo assim, questiona-se se a virtualidade já chegou à realidade dos profissionais de secretariado e, em caso afirmativo, se estes estão se adaptando a essa modalidade de trabalho flexível. Dessa forma, buscou-se verificar como se dá o ajuste dos profissionais de secretariado ao trabalho virtual.

Almeja-se contribuir para o aprofundamento dessa temática na literatura acadêmica brasileira, proporcionando ao campo de estudo uma discussão mais assertiva sobre a realidade de quem vive dentro dessa modalidade de trabalho. Além disso, visa fornecer dados e informações aos cursos de formação profissional do referido campo e o endereçamento de reflexões relacionadas aos aspectos jurídicos e legais que envolvem os contratos de trabalhos flexíveis. 


\section{Referencial Teórico}

\subsection{A virtualização do trabalho}

A palavra virtual vem do latim virtualis ou virtuale e deriva das palavras força e

potência. É empregada com frequência para significar a ausência de existência em que "o virtual $[\ldots]$ tem somente uma pequena afinidade com o falso, o ilusório ou o imaginário $[\ldots]$ ao contrário, é um modo de ser fecundo e poderoso, que põe em jogo processos de criação que perfura poços de sentido sob a platitude da presença física imediata" (Lèvi, 1996, p. 17). Assim, para Lévy (1996) virtual é entendido como uma entidade com potencial sem ter, obrigatoriamente, forma tangível ou material.

A virtualidade transfere o centro de gravidade de uma empresa ou atividade de um departamento, posto de trabalho ou livro de ponto para diferentes espaços-temporais de trabalho. Isso é o que permite a formação de equipes e profissionais virtuais com confiabilidade e baixo custo. $\mathrm{O}$ acesso a essas tecnologias, por meio de computadores, tablets e celulares, encontra-se cada vez mais ao alcance de todos, não mais apenas das grandes organizações, como também das empresas menores e até mesmo em domicílios (Barros, Vasconcelos, Silva, Brito \& Silva Filho, 2012).

Nos Estados Unidos existem indicadores do surgimento do trabalho virtual, em 1857, na companhia Estrada de Ferro Penn, que utilizava seu sistema privado de telégrafo para gerenciar os funcionários que não estavam no escritório central e com isso delegavam funções a distância (Kugelmass, 1995). No Brasil, o trabalho virtual foi introduzido, oficialmente, em 1997, no Seminário Home Office/Telecommuting - Perspectivas de Negócios e de Trabalho para o Terceiro Milênio. Em 1999, fundou-se a Sociedade Brasileira de Teletrabalho e Teleatividades (Sobratt) e segundo a entidade, o Brasil possuía, em 2008, aproximadamente, 10.6 milhões de teletrabalhadores. Em 2012, 23\% dos trabalhadores do setor privado atuavam de forma virtual de acordo com o Instituto Market Analysis.

A facilidade na aquisição de equipamentos tecnológicos permitiu que o trabalho virtual começasse a ser realizado por grandes e pequenas empresas, fazendo com que este seja vantajoso tanto para sua própria economia quanto para seu empregado. Segundo Duarte (2008), a diminuição de gastos com transporte, alimentação, combustível e infraestrutura que o trabalho remoto proporciona fez com que as empresas voltassem sua atenção para esse tipo de serviço, de forma que seus funcionários também encontrassem vantagens. Ou seja, ao 
aderir ao trabalho virtual, os empregados economizarão tempo, uma vez que passam a evitar possíveis congestionamentos, podendo realizar tarefas direcionadas ao seu próprio bem-estar.

Contudo, o crescimento desse tipo de trabalho e o sucesso das implantações, por parte das empresas, dependem do nível de ajuste dos profissionais aos aspectos que envolvem essa modalidade. Raghuram et al. (2001) dividem os fatores de ajuste em dois tipos: os estruturais e os relacionais.

Os fatores estruturais dizem respeito à dinâmica do trabalho, propriamente dito. São eles:

- independência do trabalho: refere-se à capacidade de trabalhar, de forma autônoma, distante fisicamente dos gestores e colegas de trabalho, mediante o uso de diferentes ferramentas tecnológicas (Wiesenfeld, Raghuram \& Garud, 1999; Caldwell \& Koch, 2000; Raghuram et al., 2001);

- clareza dos critérios de avaliação: envolve a construção de expectativas entre equipes e gestores, no caso da virtualidade, torna-se ainda mais importante, uma vez que os profissionais que atuam a distância possuem menos oportunidades de receber feedback (Kurland \& Egan, 1999; Raghuram et al., 2001).

Os fatores relacionais referem-se à distância psicológica entre o profissional virtualizado e a equipe ao qual pertence, tais como:

- confiança interpessoal: trata da confiança estabelecida e esperada entre as relações que envolvem os trabalhadores virtuais e seus parceiros organizacionais (Gambetta, 1988; Raghuram et al., 2001). Para Bachmann e Zaheer (2006), a confiança é como a decisão de confiar em outra parte sob uma condição de risco, até porque Lin, Standing, e Liu (2008) defendem que as boas relações interpessoais entre os componentes de uma equipe aumenta a efetividade nas coordenações das tarefas, inclusive a distância;

- conectividade organizacional: o quanto os profissionais virtuais se sentem parte de uma organização, mesmo estando fisicamente distantes, isso interfere no desejo de os profissionais de continuarem com uma relação a longo prazo com seus parceiros (Baumeister \& Leary, 1995; Raghuram et al., 2001).

Esses fatores envolvem perspectivas diferentes do gerenciamento da distância física que a virtualidade pressupõe, sendo eles críticos para o sucesso desse tipo de modalidade de trabalho. Nesse sentido, Gilson et al. (2014), ao investigar dez aspectos de trabalho virtual, evidenciaram quatro deles capazes de impactar positivamente seu sucesso, justamente, por 
promoverem o aumento da eficácia do trabalho: 1) a conexão dos e entre os membros para que se sintam iguais e cooperativos na gestão de conflitos; 2) uma atmosfera social positiva e o reforço de padrões de comunicação previsíveis; 3) a existência de procedimentos formais e estruturados; e 4) o uso de recompensas de incentivo misto, inclusive baseadas em grupos.

Por outro lado, há aspectos preocupantes no processo de virtualização, já se discute a chamada "telepressão", ou seja, estudos que analisam o estresse dos profissionais gerados pela cobrança em responder rapidamente às mensagens de clientes, colegas de trabalho ou supervisores (Barber \& Santuzzi, 2015). Esses autores defendem que a telepressão "interfere no tempo de recuperação do trabalho e nos resultados relacionados ao estresse" (Barber \& Santuzzi, 2015, p. 1).

Estima-se que o trabalho virtual tenha surgido por volta de 2008 no campo de secretariado, como consequência do desenvolvimento tecnológico. Esse movimento trouxe à tona novas formas de se executar o trabalho mediante a constante busca por qualidade e eficiência, só que de forma virtual (Nonato Jr., 2009). Tópico a ser discutido a seguir.

\subsection{O trabalho virtual do profissional de secretariado}

Em 1950, no Brasil, a chegada da indústria automobilística valorizou e fortaleceu a força de trabalho da mulher como secretária exigindo dessa profissão mais qualificação e perfil ampliado (Mazulo \& Liendo, 2010). Na década de 1980, a profissão foi regulamentada, demandando, além do conhecimento técnico, o número de registro na Superintendência Regional do Trabalho e Emprego (SRTE). Dessa forma, foi nos anos de 1990 que esse profissional começou a ser moldado para trabalhar em multifunções, em um ambiente de trabalho inerentemente de pressão e a ser executado não apenas por mulheres, mas por homens também. Segundo Ribeiro, Ribeiro e Jesus (2006) a atuação secretarial destacou-se como uma peça fundamental na empresa, articulando a área administrativa e tornando-se o elo entre a companhia e seus clientes.

Faz parte do conjunto de competências do referido profissional ser inovador, criativo, empreendedor e facilitador, pois além de atender ao executivo, também trabalha para o restante da empresa (Durante \& Fávero, 2009). Exige-se para a execução de suas atividades, o conhecimento do negócio, da missão, dos produtos e dos objetivos a serem conquistados (Durante \& Fávero, 2009). 
No que tange os aspectos virtuais, Quoos et al. (2015) defendem que o escopo de trabalho do profissional de secretariado continua sendo o mesmo, tanto presencialmente, quanto virtualmente, pois essa posição permite a ele continuar prestando seus serviços com qualidade e eficiência, não importando sua localização. Para os autores, atualizações de agenda, redação, digitação, delegação de tarefas, despacho com o gestor, providências para viagens e reuniões podem ser realizadas a distância sem nenhum impacto na agilidade e qualidade dessas atividades.

Considerando que grande parte da demanda por mais agilidade e qualidade de entrega advém da competitividade acirrada dos mercados globalizados, Gomes (2007) acredita que os profissionais, especialmente os tratados neste artigo, serão estimulados a desenvolver novas posturas com vias a inovar seu comportamento no ambiente de trabalho. Dessa forma, podendo realizar e monitorar atividades virtualmente, fazendo uso da internet e suas derivações, originando o serviço de secretariado virtual, distante dos executivos e das empresas para as quais prestam esse serviço (Jakitas, 2011).

O secretariado virtual pode prestar serviços para várias empresas ao mesmo tempo, utilizando o que tiver de mais moderno em ferramentas tecnológicas, podendo ou não ter seu próprio escritório em casa ou fazendo uso de locais designados para esse fim, como os espaços de coworking (Ribeiro et al., 2006). Ao atuar de forma não presencial, mantém as atividades específicas de sua área de atuação, contudo passa a vincular-se a uma ou mais empresas, bem como a diversos executivos (Barros et al., 2012).

A opção pelo trabalho virtual vem ao encontro de uma demanda por corte de gastos nas empresas, de maneira a manter a qualidade dos serviços mediante o menor custo possível. $\mathrm{Na}$ prática, muitas vezes, o gestor não possui orçamento para contratar um profissional capacitado e dedicado integral e fisicamente alocado na empresa. Assim, o trabalho de secretariado virtual torna-se muito atrativo e rentável (Durante \& Fávero, 2009).

Quando o executivo decide contratar essa modalidade, pode escolher quais demandas lhe são mais importantes e necessárias, criando um pacote que o atenda, tais como a compra de passagens aéreas e envio dos vouchers por e-mail, utilização de aplicativos de celular para encontrar táxis e outros meios de transporte, envio de arquivos através da "nuvem", dicas de locais para almoços via mensagens e lembretes de seus compromissos e reuniões (Borges, 2015).

Telles (2013) afirma que esse tipo de serviço é indicado para pessoas que precisam de um serviço esporádico e não possuem a necessidade de ser secretariado em tempo integral. 
Fanzeres, N., \& Lima, L. C. (2018).

Quem escolhe tal modalidade adquire diversos tipos de serviços com diferentes valores e de acordo com seus próprios prazos. Para Barros et al. (2012), o trabalho virtual de secretariado continuará crescendo de forma exponencial, pois a globalização e a rapidez com que as informações são obtidas e repassadas aumentará juntamente com a demanda por esse tipo de profissional.

O profissional de secretariado que parte para essa modalidade de trabalho, ou seja, o virtual, precisa estar apto para atender seus executivos em fusos-horários diferentes, com precisão e habilidade no gerenciamento de informações e responsabilidades, levando a um outro local toda sua rotina e tarefas, como se estivesse dentro do escritório da empresa, contudo podendo estar a milhares de quilômetros de distância (Barros et al., 2012).

\subsection{O processo de regulamentação do trabalho virtual no Brasil}

Apesar das questões legais não serem o foco deste estudo, em decorrência da lacuna literária sobre o tema, optou-se por descrever, brevemente, alguns pontos de destaque. Isso porque, com o surgimento da modalidade virtual de trabalho, a legislação brasileira teve a necessidade de criar novos processos a fim de regulamentar essa prática. Entretanto, o Brasil ainda não possui uma lei específica que assegure os direitos e deveres do trabalhador virtual, apenas um projeto de lei aprovado, em 2010, que regulamenta o trabalho a distância.

$\mathrm{Na}$ Consolidação das Leis do Trabalho (CLT), artigo 83, fica definido que trabalhador a domicílio (virtual) é aquele que presta serviços em seu domicílio ou em escritórios virtuais, tendo um empregador que o remunere (Brasil, Consolidação das Leis do Trabalho. Texto do Decreto-Lei n. 5.452 , artigo $83^{\circ}$, p. 20). Ainda segundo a CLT, a definição de trabalho virtual é o trabalho que é prestado pelo funcionário em local diferente de onde a empresa se estabelece. Mesmo que o local da execução da tarefa seja outro, a lei define que não pode haver diferença entre o trabalho virtual e o trabalho executado na empresa, conforme citado no artigo $6^{\circ}$ (Brasil, Consolidação das Leis do Trabalho. Texto do DecretoLei n. 5.452, artigo $6^{\circ}$, p. 2).

No teletrabalho, importa que o trabalhador permaneça em contato com a empresa empregadora, entregando os resultados acordados por meio de informações formais, assim a pessoalidade física, legalmente, acaba deixando de ser o principal em uma relação de emprego. Da mesma forma, a subordinação legal, nessa modalidade de trabalho, significa o controle de forma indireta, o que antes era realizado pelo olho humano, na virtualidade, é 
realizado eletronicamente, sendo os resultados mensurados pela quantidade de trabalho realizado durante um tempo. Contudo, apesar do que foi descrito, há controvérsias e muito a ser discutido no trabalho virtual, especialmente, no que tange o controle da jornada de trabalho e a adequação à segurança de dados (Sako, 2012).

Para os trabalhadores virtuais ainda é possível cadastrar-se na Associação Nacional dos Centros de Negócios e Escritórios Virtuais (ANCNEV). Esta é a associação oficial no Brasil que cuida de escritórios virtuais e possui como objetivo oferecer aos profissionais e às empresas soluções completas e integradas, aumentando assim a capacidade produtiva, lucratividade e agilidade de seus negócios (Duarte, 2008).

É importante salientar que existem diferenças entre trabalho virtual e autônomo. De acordo com Jardim (2003), o trabalhador autônomo não possui nenhum vínculo empregatício com a empresa, ele organiza suas atividades e seu próprio dia de trabalho, assumindo os riscos de seu negócio e escolhendo seus clientes. O trabalhador virtual na modalidade de contratação pela empresa é subordinado a um gerente ou coordenador, e ainda que trabalhe longe do espaço físico do escritório central continua respondendo a pedidos e exigências de seu gestor.

\section{Metodologia}

Adotou-se a abordagem quantitativa com a finalidade de verificar, empiricamente, uma teoria mediante a análise de variáveis, no caso descritivas, utilizando técnicas estatísticas (Creswell, 2007). A pesquisa é bibliográfica e descritiva, por estudar as características de determinado grupo, utilizando-se de material já elaborado e, de campo, por observar os fatos e fenômenos exatamente como ocorrem no real (Gil, 2002). Além disso, tentou-se fornecer uma melhor compreensão do fenômeno estudado, contando, para isso, com uma amostra selecionada, com vistas a gerar o máximo de insights e, não necessariamente, por sua representatividade (Malhotra \& Peterson, 2006).

Num primeiro momento, levantou-se e organizou-se o conhecimento científico e materiais a serem utilizados na construção da fundamentação teórica. Na sequência, definiuse como população do estudo profissionais de secretariado que atuam virtualmente no Brasil e com algum tipo de vínculo empregatício. Assim, considerando que a amostragem é uma etapa importantíssima por ser capaz de determinar a validade dos dados obtidos (Schiffman \& 
Fanzeres, N., \& Lima, L. C. (2018).

Kanuk, 2000), esta se constituiu de forma não probabilística, acidental e intencional (Gil, 2002) com trinta e um participantes.

A amostra caracterizou-se por ter $57 \%$ de profissionais entre 25 e 35 anos, $30 \%$ entre 35 e 45 anos e 13\% acima de 45 anos. Com relação à formação acadêmica, 37\% possuem nível superior completo, 3\% superior incompleto, $40 \%$ pós-graduação completa, $20 \%$ pósgraduação incompleta. No que tange o tempo de experiência, $27 \%$ atuam de um a cino anos na profissão, $23 \%$ de cinco a dez anos, $20 \%$ de 10 a 15 anos e $27 \%$ a mais de 15 anos. Além disso, $43 \%$ trabalham em empresas de pequeno porte, $40 \%$ em empresas de médio porte e $17 \%$ em empresas de grande porte.

A coleta de dados deu-se via questionário padronizado desenvolvido com finalidade de análise de ajuste ao trabalho virtual (Raghuram et al., 2001). A escolha por esse instrumento deu-se, especialmente, por dois motivos: 1) pelo fato de os autores - Raghuram et al., 2001 - possuírem um histórico em pesquisas dessa natureza e 2) por ser um questionário já validado em estudos anteriores. O instrumento de coleta de dados é constituído por 18 perguntas fechadas, estruturadas com escala tipo Likert de concordância que variam segundo o grau de intensidade, no caso "1" para "discordo totalmente" e "7" para "concordo totalmente"). Tal escala é largamente utilizada em pesquisas organizacionais (Badri, Donald \& Donna, 1995) e as questões são divididas em quatro seções, sendo elas: independência no trabalho virtual, clareza nas avaliações e conexão organizacional, confiança interpessoal.

No tratamento dos dados coletados fez-se uso da estatística descritiva - análise univariada - possibilitando caracterizar o que é típico no grupo, indicar a variabilidade dos indivíduos no grupo e verificar como os indivíduos se distribuem em relação a determinadas variáveis (Gil, 2002). Optou-se por esse tipo de tratamento e análise por ser um estudo inicial sobre a temática, buscando atingir o objetivo proposto e permitindo uma agenda de estudos que possam aprofundar os achados deste.

Dessa forma, para a análise dos resultados, a escala Likert, inicialmente, de sete pontos foi reorganizada para seus dois extremos; logo, as respostas foram agrupadas de maneira que se tornassem "concordo" e "discordo". Entendeu-se que essa opção favoreceu a interpretação das principais diferenças entre as percepções dos respondentes, relacionadas ao ajuste a modalidade de trabalho virtual.

O questionário foi administrado por meio eletrônico (Hair et al., 2006), com coleta de dados de corte transversal (Creswell, 2007). Iniciou-se com a tradução das questões do inglês para o português e formatação dentro do site Survey Monkey. Na sequência, realizou-se 
um pré-teste para verificação da compreensão semântica do instrumento, resultando na validação da tradução. Com isso pronto, o link da pesquisa foi divulgado ao público-alvo. A pesquisa apresentou dificuldades na obtenção de respondentes, foi preciso checar com estes se atuavam de fato de forma virtual, resultando no descarte de $10 \%$ dos questionários (totalizando 31 respostas para serem utilizadas na pesquisa).

\section{Discussão e Interpretação dos Resultados}

Inicialmente serão apresentados os resultados referentes aos fatores estruturais e, sequencialmente, os relacionais, conforme tratado por Raghuram, Garud, Wiesenfeld e Gupta (2001). Por fim, serão sintetizadas as percepções sobre o ajuste global, dos profissionais de secretariado participantes desta investigação, ao trabalho virtual.

\subsection{Fatores estruturais}

\subsubsection{Independência no trabalho virtual}

A Tabela 1 refere-se às questões de um a três e abordaram a independência profissional no trabalho virtual. Com relação à possibilidade do desempenho profissional depender do trabalho de outros, observou-se uma polaridade de respostas, ou seja, $40 \%$ dos participantes concordam e discordam, concomitantemente. Contudo, observou-se uma ligeira diferença dos respondentes no que tange a preferência por trabalhar de forma dependente, ou seja, uma pequena maioria (40\%) afirmam preferir trabalhar com o outro, contra $37 \%$ que consideram a independência a melhor forma de alcançar melhores desempenhos. Talvez porque uma expressiva maioria $(67 \%)$ considera que suas atividades/projetos são desenvolvidos de forma independente.

Tabela 1 - Independência no trabalho virtual

\begin{tabular}{|l|l|l|}
\hline & Concordam & Discordam \\
\hline $1-$ Meu desempenho não depende de trabalhar com outras pessoas & $40 \%$ & $40 \%$ \\
\hline $\begin{array}{l}2-\text { Para alcançar meu melhor desempenho, prefiro trabalhar de forma } \\
\text { independente }\end{array}$ & $37 \%$ & $40 \%$ \\
\hline
\end{tabular}

R.G. Secr., GESEC, São Paulo, v. 9, n. 1, p 42-64, jan./abr. 2018. 
Esses achados destacam que o fato de o desempenho depender da atividade individual, ou seja, de forma independente do grupo, deve-se, provavelmente, ao escopo de trabalho do secretariado que parece continuar sendo o mesmo, tanto presencialmente quanto distante do escritório (Quoos et al., 2015). Porém, isso não significa que o profissional de secretariado prefira desenvolver as atividades virtuais totalmente de forma "autônoma".

Possivelmente, essa preferência se dê em decorrência de imprevistos que possam surgir no andamento de suas atividades, isso porque, Raghuram et al. (2001, p.387) consideram que "a autonomia é facilitada à medida que os indivíduos trabalham assincronamente ao acessar bases de dados comuns por meio de intranets e extranets, seguros no conhecimento de que podem se conectar com outros em caso de restrições ou oportunidades imprevistas".

\subsubsection{Clareza nas avaliações}

A Tabela 2 apresenta as questões de quatro a seis e abrangeram a clareza nas avaliações do trabalho virtual. De forma geral, observa-se que o sistema de gestão de desempenho, ou seja, os critérios, a forma de mensurar e a clareza desse conjunto, parece satisfazer a maioria dos participantes. Isso porque $63 \%$ concordam que os critérios são objetivos, $77 \%$ concordam que há facilidade em medir e avaliar seus desempenhos e $67 \%$ afirmam que as medidas de seus desempenhos são claras.

Tabela 2 - Clareza em gestão do desempenho

\begin{tabular}{|l|l|l|}
\hline & Concordam & Discordam \\
\hline $4-$ Existem critérios objetivos que avaliam meu desempenho & $63 \%$ & $23 \%$ \\
\hline $5-$ É fácil medir e avaliar meu desempenho & $77 \%$ & $13 \%$ \\
\hline 6 - As medidas da meu desempenho são claras & $67 \%$ & $20 \%$ \\
\hline
\end{tabular}

Fonte: Autores.

R.G. Secr., GESEC, São Paulo, v. 9, n. 1, p 42-64, jan./abr. 2018. 
A virtualidade não parece ser um obstáculo para avaliar o desempenho do profissional de secretariado pois os achados demonstram que é possível fazê-lo distante da empresa. Barros et al. (2012) acredita que a alta tecnologia utilizada no trabalho virtual torna as medidas de performance, fora do ambiente de trabalho, fáceis e claras. Dessa forma, não sendo preciso estar no mesmo local em que o gestor para realizar esse tipo de avaliação, preservando a qualidade, agilidade e eficiência necessárias a esse processo de gestão.

Raghuram et al. (2001) defendem que a clareza nos critérios de avaliação de desempenho podem favorecer vínculos de longo prazo entre o profissional virtual e seu empregador. Nesse sentido, identificou-se que mais de $50 \%$ dos respondentes tendem a desenvolver longos relacionamentos de trabalho com seus atuais contratantes.

\subsection{Fatores Relacionais}

\subsubsection{Conectividade organizacional}

A Tabela 3 apresenta as questões de sete a nove que trataram da conexão com a organizacional no trabalho virtual. Em aspectos amplos, essas questões identificam o senso de pertencimento e possibilidade de crescimento dos profissionais virtuais com relação a empresa.

Os resultados evidenciam que, apesar da distância física, os profissionais de secretariado mostram-se cientes dos problemas de dentro da empresa que podem influenciar seus planos de carreira (90\%), também estão atualizados quanto às oportunidades de destaque e visibilidade no trabalho (70\%) e parecem sentir parte da comunidade empresarial, pois apenas $17 \%$ não concordam que os eventos sociais são adequados.

\section{Tabela 3 - Conexão com a organização}

\begin{tabular}{|l|l|l|}
\hline & Concordam & Discordam \\
\hline $\begin{array}{l}7-\text { Estou ciente dos problemas na empresa que podem influenciar meu plano } \\
\text { de carreira }\end{array}$ & $90 \%$ & $3 \%$ \\
\hline $8-$ Estou ciente das oportunidades no trabalho & $70 \%$ & $13 \%$ \\
\hline $\begin{array}{l}9-\text { Os eventos sociais na empresa são adequados para construção de senso } \\
\text { de comunidade }\end{array}$ & $63 \%$ & $17 \%$ \\
\hline
\end{tabular}

Fonte: Autores. 
Fanzeres, N., \& Lima, L. C. (2018).

A conexão que deve ser criada entre a empresa e o secretariado virtual mostrou-se tão importante quanto efetiva para que o trabalho seja bem desenvolvido, primando tanto pela realização dos resultados quanto pelo senso de comunidade. Para Raghuram et al. (2001), a gestão de profissionais virtuais requer habilidade e transparência, fazendo com que o empregado esteja ciente de suas oportunidades mesmo estando distante fisicamente da organização.

A criação de situações para se construir um ambiente comunitário favorece a conexão entre o profissional que trabalha de forma virtual e a empresa. Os resultados demonstrados na Tabela 3 destacam que empresas que adotam essa modalidade de trabalho conseguem desempenhá-la de forma bastante satisfatória e criam esse sentimento em seus times de teletrabalho.

\subsubsection{Confiança interpessoal}

A Tabela 4 apresenta as questões de dez a treze referentes à confiança interpessoal no trabalho virtual. Uma ampla maioria (acima de 70\% dos respondentes) demonstram que a questão da confiança, seja entre os profissionais ou com relação aos gestores, não parece ser um ponto dificultador da modalidade de trabalho discutida neste artigo.

Quanto a acreditar que as reuniões dentro da empresa são adequadas para criar bons relacionamentos, $73 \%$ concordam e 10\% discordam. Em relação a confiar em seus superiores, $70 \%$ concordam e apenas $10 \%$ discordam. Considerando a confiança em seus colegas, $80 \%$ afirmam ter essa relação, da mesma forma que acreditam ser recíproco (confiança no respondente, $80 \%$ concordam).

Tabela 4 - Confiança interpessoal

\begin{tabular}{|l|l|l|}
\hline & Concordam & Discordam \\
\hline $10-$ Reuniões na empresa são adequadas para criar bons relacionamentos & $73 \%$ & $10 \%$ \\
\hline $11-$ Confio em meus superiores & $70 \%$ & $10 \%$ \\
\hline $12-$ Confio em meus colegas & $80 \%$ & $7 \%$ \\
\hline $13-$ Os colegas confiam em mim & $80 \%$ & $3 \%$ \\
\hline
\end{tabular}

Fonte: Autores.

R.G. Secr., GESEC, São Paulo, v. 9, n. 1, p 42-64, jan./abr. 2018. 
A distância física do ambiente de trabalho pode ser prejudicial para o relacionamento entre colegas e gestores e provocar o insucesso do projeto. Em contrapartida, quando o profissional virtual se integra e cria relações de confiança, seu desempenho pode, inclusive, aumentar. Isso porque, empregados que confiam em seus superiores e em seus colegas de trabalho conseguem desempenhar muito melhor suas funções, ainda que virtualmente (Raghuram et al., 2001). Para os autores, relações profissionais que são baseadas em confiança tendem a ser mais duráveis e proporcionam um ambiente de trabalho equilibrado mesmo à distância.

Os achados apresentados da Tabela 4 indicam que a maior parte dos entrevistados neste estudo, confia em seus colegas e gestores, logo, tendem a criar bons relacionamentos na empresa por essa razão. Para Obisi (2016) profissionais que se sentem satisfeitos com suas relações de trabalho, mesmo atuando virtualmente, podem influenciar os níveis de comprometimento com a organização.

O cerne da confiança interpessoal reside no impacto da distância psicológica, uma vez que o empregado não convive - fisicamente - com os demais parceiros de trabalho (O’Hara-Devereaux \& Johnson, 1994). Os resultados deste estudo demonstram que a distância física não está se transformando em distância psicológica, significando que a grande maioria dos profissionais de secretariado, que participaram desta investigação, se sente parte da organização, compartilhando de uma identidade social em seus grupos de trabalho (Boros et al., 2010).

Apesar da questão da liderança ter sido abordada de forma superficial, percebe-se uma crescente demanda investigativa no âmbito internacional sobre a interação entre gestores e o trabalho virtual. Os estudiosos dessa temática vêm descobrindo, entre outras coisas, que a virtualidade pode atenuar a relação entre a hierarquia e o desempenho, ao mesmo tempo, é capaz de aprimorar a relação entre os apoios estruturais e o desempenho (Gilson et al., 2014).

\subsubsection{Ajuste Global Ao Trabalho Virtual}

A Tabela 5 trata das questões de quatorze a dezoito e retrata o ajuste global do profissional ao trabalho virtual. Verificou-se que mesmo $27 \%$ dos respondentes afirmando que se tiverem a oportunidade de retornar ao ambiente tradicional (não virtual) estariam propensos em aceitar, todos os outros quesitos de ajuste mostram-se bem favoráveis, tais como: $87 \%$ estão satisfeitos em trabalhar de forma virtual; $73 \%$ consideram que trabalhar virtualmente 
Fanzeres, N., \& Lima, L. C. (2018).

proporciona mais eficiência do que dentro da empresa; $77 \%$ afirmam que trabalhando virtualmente foram capazes de equilibrar a vida pessoal e profissional e $70 \%$ advogam que a produtividade aumentou.

Essa satisfação, muitas vezes, relaciona-se a variáveis intervenientes tais como a oportunidade de aprendizado, o estabelecimento de metas, uma gestão adequada de conflitos por parte dos gestores e boas capacidades tecnológicas (Gilson et al., 2014). Mesmo assim, o ajuste ao trabalho virtual, por parte dos profissionais de secretariado, apresenta-se de forma bastante positiva.

Tabela 5 - Ajuste ao trabalho virtual

\begin{tabular}{|l|l|l|}
\hline & Concordam & Discordam \\
\hline $14-$ Estou satisfeito em trabalhar virtualmente & $87 \%$ & $3 \%$ \\
\hline $\begin{array}{l}15-\text { Trabalhar virtualmente permite ser mais eficiente do que trabalhar em } \\
\text { uma empresa }\end{array}$ & $73 \%$ & $3 \%$ \\
\hline $\begin{array}{l}16-\text { Se tiver oportunidade de retornar ao ambiente tradicional de empresa } \\
\text { (de forma não virtual), estaria propenso em não aceitar }\end{array}$ & $53 \%$ & $27 \%$ \\
\hline $\begin{array}{l}17-\text { Desde que comecei a trabalhar virtualmente, fui capaz de equilibrar } \\
\text { melhor minha vida pessoal e profissional }\end{array}$ & $77 \%$ & $7 \%$ \\
\hline $\begin{array}{l}18-\text { Desde que comecei a trabalhar virtualmente senti que minha } \\
\text { produtividade aumentou }\end{array}$ & $70 \%$ & $10 \%$ \\
\hline
\end{tabular}

Fonte: Autores.

Esses achados parecem demonstrar que a telepressão (Barber \& Santuzzi, 2015) não parece afetar o grupo participante do estudo, uma vez que este se mostra satisfeito com sua condição de trabalho, o que é confirmado, também, pelos resultados sobre o equilíbrio entre vida profissional e pessoal.

No que tange o aumento da produtividade via trabalho virtual, há estudos que evidenciam o impacto tanto positivo, quanto negativo na efetividade dos resultados dos projetos (Gilson et al, 2014). Dentro da perspectiva positiva, os achados vão ao encontro da argumentação de Obisi (2016) e Thompson e Caputo (2009) sobre a razão do aumento de produtividade. Para os referidos autores, essa é incentivada por corrigir possíveis conflitos entre empregador-empregador. 
É preciso que o profissional de secretariado, interessado em atuar de forma virtual, estude e se inteire sobre essa modalidade, para ter certeza de que se adequará e conseguirá atingir bons resultados. Segundo Gomes (2007), o ajuste ao trabalho virtual é extremamente importante para que o profissional desempenhe de forma impecável essa função. De acordo com o autor, é preciso ter facilidade em trabalhar a distância e reconhecer que existem inúmeras vantagens que só esse tipo de modalidade pode proporcionar.

\section{Considerações Finais}

Este artigo buscou verificar como se dá o ajuste, pelo profissional de secretariado, ao trabalho virtual. Dentre os achados, destacam-se: 1) a clareza do sistema de avaliações, referente aos fatores estruturais; e 2) a relação de confiança interpessoal, pertencente aos fatores relacionais. Isso porque esses aspectos apresentam os maiores índices de concordância por parte dos participantes.

Verificou-se que, de forma geral, os respondentes se mostram satisfeitos em trabalhar de forma virtual (87\%) evidenciando o ajuste desses profissionais a esse tipo de modalidade de trabalho flexível. Além disso, o fato de $70 \%$ dos participantes afirmarem ter aumento de produtividade e $77 \%$ defenderem que há equilíbrio entre vida pessoal e profissional atuando de forma virtual demonstra que a telepressão não parece os afetar esse público.

Entende-se que esses achados são preliminares, especialmente, ao se tratar dos profissionais de secretariado, diante da escassez de literatura científica que une essa temática a de trabalho virtual. Contudo, espera-se contribuir para o aprofundamento dos diversos campos de estudos que permeiam a questão da virtualidade. Também, podem ser aproveitados para reflexões tanto por parte das empresas, que almejam implantar esse tipo de modalidade de trabalho, quanto por parte dos profissionais. Com relação a tais profissionais, destaca-se a importância de uma qualificação que suporte a constituição de uma identidade profissional diferente da tradicional, em que os diversos fatores constituintes do sucesso desse tipo de trabalho sejam aprimorados.

Por acreditar que o teletrabalho é um percurso de uma via sem retorno, sugere-se a continuidade deste estudo, especialmente, com uma abordagem qualitativa que possa explicar, com profundidade, os resultados obtidos neste artigo, e indo além, compreendendo o sentimento que os profissionais possuem em suas rotinas. 
Fanzeres, N., \& Lima, L. C. (2018).

Apesar das questões jurídicas terem sido tratadas apenas de forma teórica e brevemente, considera-se uma limitação do estudo. Além disso, os resultados deste artigo não podem ser generalizáveis, ou seja, não é possível concluir que todo profissional de secretariado se adaptará à modalidade virtual de trabalho. Dessa forma, sugere-se, para investigações futuras, que sejam explorados de forma comparativa, o trabalho virtual com outros tipos de flexibilidade no ambiente de trabalho. Sem contar que a abordagem qualitativa também poderia fornecer considerações relevantes a referida temática.

\section{Referências}

Bachmann, R. \& Zaheer, A. (2006). Handbook of trust research. Cheltenham: Edward Elgar Publishing Limited.

Badri, M. A., Donald, D., \& Donna, D. (1995). A study of measuring the critical factors of quality management. International Journal of Quality \& Reliability Management, 12, 2, 36-53.

Barber, L. K., \& Santuzzi, A. M. (2015). Please respond ASAP: Workplace telepressure and employee recovery. Journal of Occupational Health Psychology, 20(2), 172-189.

Barros, C. M. P. Vasconcelos, L. S., Silva, J. S. S., Brito, D. G. S., \& Silva Filho, M. C. (2006). A virtualidade no mundo do trabalho: um estudo sobre a atuação do secretário executivo virtual. Revista expectativa, Cascavel, 11, 59-81.

Baumeister, R. F., \& Leary, M. R. (1995). The need to belong: Desire for interpersonal attachments as a fundamental human motivation. Psychological Bulletin, 117(3), 497529.

Borges, B. (2015). Como a tecnologia se tornou um agente de mudança na profissão de secretariado. Recuperado em 4 de outubro, 2016, de $<$ http://manualdasecretaria.com.br/2015/09/28/como-a-tecnologia-se-tornou-um-agentede-mudanca-na-profissao-de-secretariado/>. 
Boros, S., Meslec, N., Curseu, P. L., \& Emons, W. (2010). Struggles for cooperation: Conflict resolution strategies in multicultural groups. Journal of Managerial Psychology, 25, 539554.

Brasil. Decreto-lei n. 5.452, de $1^{\mathrm{o}}$ de maio de 1943. Recuperado em 14 de outubro, 2016, de $<$ http://www.trtsp.jus.br/geral/tribunal2/LEGIS/CLT/INDICE.html>.

Brasil. Consolidação das Leis do Trabalho, Código de Processo Civil, Legislação trabalhista e processual trabalhista, Legislação Previdenciária e Constituição Federal. Organização Nelson Mannrich. - 9 ed. rev., ampl. e atual. São Paulo: Editora Revista dos Tribunais, 2008 .

Brasil Labore. Histórico e tendências do home office / teletrabalho / trabalho remoto. Disponível em: <http://www.brasillabore.com.br/sobre/home-office/>. Acesso em: 04 out. 2016.

Caldwell, D. F., \& Koch, J. L. (2000). The impact of mobile computing on work groups. In T. L. Griffith, M. A. Neal \& E. A. Mannix (Eds.), Technology (pp. 133-156). Stamford, CT: JAI Press.

Creswell, J. W. (2007). Projeto de pesquisa: métodos qualitativo, quantitativo e misto (2a ed.). Porto Alegre: Artmed.

Duarte, L. G. (2008) Teletrabalho: um novo modelo de trabalho. Âmbito Jurídico, 59, Recuperado em 3 de novembro, 2016, de $<$ http://www.ambitojuridico.com.br/site/index.php?n_link=revista_artigos_leitura\&artigo _id $=5352>$.

Durante, D. G. \& Pontes, E. S. (2015). Produção intelectual em Secretariado Executivo: estudo na Revista de Gestão e Secretariado (GeSec). Revista de Gestão e Secretariado GeSec, São Paulo, 6, 23-47.

Durante, D. G. \& Fávero, A. A. (Orgs.) (2009). Gestão secretarial: formação e atuação profissional. Passo Fundo: Universidade de Passo Fundo.

Ferreira Júnior, J. C. (2010). Telecommuting: o paradigma de um novo estilo de trabalho. Revista de administração de empresas, 40, 8-17. 
Fanzeres, N., \& Lima, L. C. (2018).

Gambetta, D. (Ed.) (1988). Trust Making and breaking cooperative relations. Oxford Blackwell.

Gil, A. C. (2002). Como elaborar projetos de pesquisa (4a ed.). São Paulo: Atlas.

Gilson, L. L. et al. (2014). Virtual teams research 10 years, 10 themes, and 10 opportunities. Journal of Management, 41, 1313-1337.

Gomes, A. R. (2007). Parceria entre o executivo e o profissional de secretariado. Mito ou realidade? Trabalho de Conclusão de Curso (Bacharelado em Secretariado), Universidade Federal do Ceará, Fortaleza.

Hair, J.F., Babin, B., Money, A.H. \& Samuel, P. (2006). Fundamentos métodos de pesquisa em administração. Porto Alegre: Bookman.

Harvard Business Review (2016). The third wave of virtual work. Recuperado em 10 de Agosto, 2016, de https://hbr.org/2013/01/the-third-wave-of-virtual-work>.

Iizuka, E. S. \& Almeida, W. A. G. (2014). Produção acadêmica em secretariado: análise dos artigos da Revista de Gestão e Secretariado (GeSec) e da Revista Secretariado Executivo em Revist@entre 2005 e 2012.Revista de Gestão e Secretariado-GeSec, 5, 71-93.

Jakitas, R. (2011). Pequena empresa aposta em secretária virtual. Recuperado em 15 de outubro, 2016, de <http://economia.estadao.com.br/noticias/negocios,pequena-empresaaposta-em-secretaria-virtual,97359e $>$.

Jardim, C. C. S. (2003). O teletrabalho e suas atuais modalidades. São Paulo: Ltr.

Johns, T. \& Gratton, L. (2016). The third wave of virtual work. Harvard Business Review. Recuperado em 10 de Agosto, 2016, de https://hbr.org/2013/01/the-third-wave-of-virtualwork $>$.

Kugelmass, J. (1995). Telecommuting: a manager's guide to flexibe work arrangements. Mendocino: Lexington Books.

Kurland, N. B., \& Egan, T. (1999). Public vs. private perceptions of formalization, outcomes and justice. Journal of Public Administration Research and Theory, 3, 437-580. http://dx.doi.org/10.1093/oxfordjournals.jpart.a024417 
Lévy, P. (1996). O que é virtual? Rio: Editora 34.

Lin, C.; Standing, C. \& Liu, Y. (2008). A model to develop effective virtual teams. Decision Support System. 45, 1031-2045.

Malhotra, N. K., \& Peterson, M. (2006). Basic marketing research. International Edition.

Martins, C. B., Maccari, E. A., Silva, A. O. \& Todorov, M. C. A. (2014). Retrato dos periódicos científicos de secretariado no Brasil. Ecco S Revista Científica, 34, 63-83.

Mazulo, R. \& Liendo, S. (2010). Secretária: rotina gerencial, habilidades comportamentais e plano de carreira. São Paulo: Senac.

Nonato Júnior, R. (2009). Epistemologia e teoria do conhecimento em secretariado executivo: a função das ciências da assessoria. Fortaleza: Expressão Gráfica.

Obisi, C. (2016). The empirical validity of the adjustment to virtual work arrangement by business organisations in Anambra State, Nigeria. International Journal of Scientific Research in Education, 9, 173-181.

O’Hara-Devereaux, M. \& Johnson, R. (1994). Global work: bridging distance, culture and time. San Francisco, CA: Jossey-Bass.

Quoos, A. B., Pinto, L., Rodrigues, R., \& Goulart, C. G. (2015). Secretariado a distância: um estudo sobre sua viabilidade nos diversos segmentos de mercado. Anais da mostra cientifica do Cesuca. Recuperado em 27 de outubro, 2016, de $<$ http://ojs.cesuca.edu.br/index.php/mostrac/article/view/961>.

Raghuram, S. et al. (2001). Factors contributing to virtual work adjustment. Journal of Management, 383-405.

Ribeiro, N. L. A., Ribeiro, L. M., \& Jesus, R. A. (2006). Tecnologia: avanços facilitadores do trabalho secretarial. Recuperdo em 3 de outubro, 2016, de https://scientificproductionset.wikispaces.com/file/view/tecnologia_avancos_facilitadores do trabalho secretarial.pdf. 
Fanzeres, N., \& Lima, L. C. (2018).

Sako, E. S. A. (2012). Teletrabalho telessubordinado, dependente e por conta alheia: reengenharia dos requisitos da relação empregatícia. Revista TST, 78, 17-36.

Schiffman, L. \& Kanuk, L. (2000). Comportamento do consumidor (6a ed.) Rio de Janeiro: LTC Editora.

Silva, A. M. S. (2015). A aplicação do teletrabalho no serviço público brasileiro. Anais do $3^{o}$ Congresso Internacional de Direito e Contemporaneidade: mídias e direitos da sociedade em rede.

Telles, M. (2013). Assistentes virtuais podem simplificar sua vida. Recuperado em 10 de outubro, 2016, de <http://status-assistentevirtual.blogspot.com.br>.

Thompson, C. \& Caputo, P. (2009). The reality of virtual work: Is your organization ready? Retrieved February 24, 2016 from http://www.aon.com/attachments/virtual_worker_ whitepaper.pdf

Winter, V. R. L. (2005). Uma forma alternativa de emprego. São Paulo: Ltr. 